\title{
(2) OPEN ACCESS \\ Neonatal Escherichia coli infection in twins: clinical spectrum and management dilemma
}

\author{
Dylan Ehman, ${ }^{1,2}$ Veronica Mugarab Samedi (D) ,'2 Kaarthigeyan Kalaniti (D) , 1,2 \\ Sibasis Daspal ${ }^{1,2}$
}

${ }^{1}$ Royal University Hospital, Saskatoon, Saskatchewan, Canada

${ }^{2}$ College of Medicine, University of Saskatchewan, Saskatoon, Saskatchewan, Canada

Correspondence to Dr Veronica Mugarab Samedi; vmsamedi@gmail.com

Accepted 30 December 2020

A Check for updates

(c) BMJ Publishing Group Limited 2021. Re-use permitted under CC BY-NC. No commercial re-use. See rights and permissions. Published by BMJ.

To cite: Ehman $D$

Mugarab Samedi $V_{\text {, }}$

Kalaniti K, et al. BMJ Case

Rep 2021:14:e238470

doi:10.1136/bcr-2020-

238470

\section{SUMMARY}

The clinical manifestation of Escherichia coli could vary from asymptomatic bacteraemia to systemic bloodstream infection and meningitis. We describe an unusual course of $E$. coli infection in twins, emphasising commencement of appropriate antimicrobial therapy. A set of male dichorionic diamniotic twins were delivered at 34 weeks of gestation by caesarian section. Pregnancy was complicated by diabetes, preeclampsia and cholestasis. Antenatal ultrasounds noted a congenital pulmonary airway malformation in twin $A$. Following delivery, twin A developed respiratory distress, but twin B was asymptomatic. Partial septic work-up at admission in the neonatal intensve care unit was done. Twin A's blood culture grew E. coli, while twin B's blood culture was negative. Twin A was treated with 7 days of intravenous antibiotics. At 11 days of age, twin B acutely developed a scrotal swelling. On suspicion of testicular torsion, he was taken for urgent surgery, which revealed a scrotal abscess positive for $E$. coli. The scrotum was irrigated and successfully treated with 4 weeks of antibiotics. Both twins were doing well at 3 months of follow-up.

\section{BACKGROUND}

Escherichia coli infection is a significant cause of mortality and morbidity in neonates, especially those born preterm. It is a major aetiology of a range of clinical presentations, including sepsis, pneumonia, meningitis, and skin and soft tissue infections. Early-onset sepsis (EOS), occurring in the first week of life, is an especially significant concern, with a mortality rate over $10 \%$. In Canada, E. coli has surpassed group B Streptococcus (GBS) as the most common cause of EOS as screening and prophylactic intrapartum antibiotics have become the standard of care. ${ }^{2}$

A number of risk factors for EOS have been identified, but the only recommendation is by the American Academy of Pediatrics (AAP) for asymptomatic siblings of a patient with EOS in a multigestational pregnancy is close observation, as EOS is usually caused by vertical transmission from the mother. ${ }^{3}$ In a small case series and literature review, Almidani et al found a wide variation in practice and no consensus on management in this situation. ${ }^{4}$

Here we discuss a set of twins born prematurely, one with early respiratory distress and bacteraemia, and the other with a late presentation of scrotal abscess, both caused by the same organism, E. coli. This case highlights the clinical spectrum of neonatal E. coli infections, including the rare occurrence of scrotal abscess, as well as the potential need for treatment in twins when one twin has EOS.

\section{CASE PRESENTATION}

A 24-year-old gravida 2, para 1 woman delivered a set of male dichorionic diamnioticdichorionic diamniotic twins, at 34 weeks gestation by urgent caesarian section for an atypical fetal heart rate in twin A, after presenting to care for reduced fetal movement. She was not in labour and membranes were intact at delivery.

Pregnancy had been complicated by gestational diabetes, pre-eclampsia, and cholestasis of pregnancy, for which she was on insulin, labetalol and ursodiol, respectively. Her serologies were all protective, including negative GBS status. Antenatal ultrasounds had noted an incidental congenital pulmonary airway malformation (CPAM) in twin A but were otherwise normal.

At delivery, twin A needed positive pressure ventilation for poor respiratory effort followed by continuous positive airway pressure (CPAP) support for increased work of breathing. Twin B was delivered a minute after twin $\mathrm{A}$ and was vigorous and did not require any resuscitation. Both infants were admitted to the neonatal intensive care unit (NICU) for prematurity and assessment of twin A's CPAM.

In the NICU, twin A underwent partial septic workup, including blood cultures at admission, and was started on prophylactic intravenous antibiotics. White blood cell (WBC) count was $3.67 \times 10^{9} / \mathrm{L}$. Chest radiography initially showed ground-glass signs of respiratory distress syndrome, but a repeat chest X-ray prior to discharge demonstrated a focal confluent density in the posterior left hemithorax highly suggestive of CPAM. This did not require inpatient intervention by paediatric surgery. Conversely, twin B did well and received routine care.

Twin A was trialled off CPAP to room air at 24 hours of life. At this time, twin A's blood culture was reported as positive for E. coli. Following this result, blood cultures were repeated on both twins, which were negative at 48 hours. Twin B did not receive antibiotics as he was clinically well. Twin A received a total of 7 days of intravenous antibiotics for a suspected diagnosis of pneumonia, considering his respiratory distress and history of CPAM.

At 11 days of age, twin B's right scrotum became swollen, erythematous and tender. He was afebrile and had no other signs of infection. Suspecting testicular torsion, he was urgently taken to the operating room for right inguinal and scrotal exploration. Surgery revealed a scrotal abscess present 
just outside the patent tunica vaginalis, with swelling of the right testicle, epididymis, vas deferens and testicular vessels. The right testicle appeared viable and an orchidopexy was performed. The scrotum was irrigated after the abscess was drained, and samples were collected for pathology and cultures. A vessel loop drain was inserted, communicating from the right scrotum to the inguinal region. Diagnostic laparoscopy of the peritoneum through the patent vaginal process prior to its ligation demonstrated no necrotising enterocolitis or otherwise abnormal bowel. The surgery was completed without complications.

The infant was treated with intravenous vancomycin and cefotaxime. WBC count following surgery was $14.87 \times 10^{9} / \mathrm{L}$ and C reactive protein was $53.6 \mathrm{mg} / \mathrm{L}$. Pathology confirmed the diagnosis of right testicular abscess. Both blood and abscess culture were positive for E. coli. An abdominal ultrasound to assess for an intra-abdominal source for the abscess found no signs of infection. Antibiotics were switched to ampicillin based on the culture and sensitivity results. E. coli meningitis was ruled out based on cerebral spinal fluid analysis and culture in both twins. The remainder of both twins' clinical course in the NICU was unremarkable. Twin B's drain was removed 6 days after surgery. He was stepped down to oral amoxicillin after 9 days of intravenous antibiotics, with a plan to complete a total of 4 weeks of antibiotics. Twin A was discharged at 16 days of life and twin B was discharged at 20 days of life.

\section{OUTCOME AND FOLLOW-UP}

At 3 months of follow-up, both twins were doing well. Twin A had no further issues with his CPAM and twin B's scrotum had healed well with no further testicular concerns.

\section{DISCUSSION}

Infection by E. coli in the neonatal period is an important health concern. However, data about the incidence, distribution and clinical manifestations of neonatal E. coli infections remain limited and controversial.

In last decade, E. coli surpassed GBS as the most common cause of neonatal bacteraemia in premature and term newborns. Despite the implementation of comprehensive infection control measures, E. coli in this population is a common cause of severe infections, including meningitis, with mortality rate as high as $40 \%$. Studies in both Canada and the USA demonstrate increasing rates of EOS due to E. coli, as well as high rates of resistance to ampicillin and gentamycin, commonly used empiric antibiotics for EOS. ${ }^{5}$ The outcome of E. coli infections is frequently poor, with a high rate of devastating consequences associated with severe neurodevelopmental disabilities in survivors. Awareness of the potential fulminant sepsis caused by E. coli, as well as the diversity of other clinical presentations of this infection, is essential for effective prevention and management.

In the early neonatal period, less than 7 days of age, majority of $E$. coli infection presents as respiratory distress progressing to haemodynamic instability. However, in older neonates, it can cause isolated pneumonia, localised skin infection and abscess, asymptomatic bacteraemia and meningitis. Maternal risk factors for EOS caused by E. coli and GBS include positive GBS surveillance, GBS bacteriuria, previous infant with EOS, prolonged rupture of membranes and maternal fever. ${ }^{1}$ Risk factors specific to E. coli EOS include prematurity, low birth weight and maternal chorioamnionitis. ${ }^{5}$ Of these, the only present risk factor for either twin was prematurity. Also relevant to this case, the presence of a CPAM is an independent risk factor for neonatal respiratory distress and respiratory tract infection. ${ }^{6}$
In our case, the signs of EOS in twin A was recognised early, and 7 days of intravenous antibiotic treatment was effective. It is important to note, however, that current guidelines recommend a course of intravenous antibiotics of 10-14 days for uncomplicated early-onset bacteraemia caused by E. coli. ${ }^{7}$ There was a management dilemma regarding his twin, who was asymptomatic. Transmission of bacteria causing EOS is usually vertical from the mother, so twin B was high risk but did not have the additional risk factors (eg, CPAM). The only guideline in this scenario is from the AAP, which recommends close observation of the asymptomatic sibling, with investigations and empiric treatment if symptoms occur. ${ }^{3}$ In one small case series of twins with one sibling being investigated for EOS from Canada, just over a third of asymptomatic neonates with risk factors were investigated and empirically treated. ${ }^{4}$ There have been no studies showing incidence of EOS in an asymptomatic twin of a patient with EOS, likely due to rarity.

In our case, twin B was not initially investigated at admission, although a blood culture was drawn when twin A was diagnosed with EOS, and the blood culture was negative. This blood culture could have been a false negative, since blood cultures in neonates are highly dependant on technique and volume. E. coli infections, in particular, can result in low levels of bacteraemia, which could be hard to detect. ${ }^{8}$

Acute scrotal swelling is uncommon in the neonatal period, and differential diagnosis includes hernia, hydrocele, testicular torsion and infection. Infection is usually bacterial or viral epididymitis and orchitis but can rarely manifest as bacterial abscess. ${ }^{9}$ Acute scrotal swelling is a surgical emergency, as testicular torsion cannot usually be ruled out clinically, and urgent intervention is required to prevent loss of testicular viability. Fever and tenderness need not be present in infectious causes compared with torsion. ${ }^{10}$ The cremasteric reflex may be lost in non-torsion etiologies, and 50\% of normal newborns will not have the reflex. ${ }^{11}$ Ultrasound is commonly used in older patients to guide management, but testicular artery flow is frequently undetectable on Doppler ultrasonography in normal prepubescent testicles, making it ineffective in neonates. ${ }^{12}$

Scrotal abscess in neonates are a rare finding. Bacteria can be seeded haematogenously following bacteraemia, secondary to an intra-abdominal infection through a patent processus vaginalis or via the urogenital tract. ${ }^{1013}$ Haematogenous spread would have been the most likely vector for twin B's scrotal absces, which developed acutely at 11 days of life. He had no preceding signs of urinary tract infection, such as feeding intolerance or vital sign changes, which would have suggested a genitourinary route; however, this cannot be entirely excluded as a urine culture was not collected. There was a patent processus vaginalis, but peritoneal cultures taken intraoperatively did not show E. coli and there were no signs of infection seen laparoscopically to suggest the abdominal route of infection. A common origin for the $E$. coli in both twins was suggested by the almost identical antibiotic sensitivities from each culture.

Scrotal abscess is effectively managed with incision and drainage, and a course of antibiotics specific to the infectious agent. Grampositive bacteria is usually implicated, but abscesses due to Klebsiella pneumoniae, E. coli and Candida albicans have been reported. ${ }^{14}{ }^{15}$ Abscess due to $E$. coli, as was the case here, appears extremely rare, with only four reported cases in the literature. ${ }^{16-19}$ Even if the testicle appears severely inflamed, necrosis is rare and the testicle can usually be salvaged. ${ }^{20}$ The postoperative course in our case was uncomplicated and the patient completed treatment without sequelae. 
Healthcare practitioners should be vigilant in identifying neonates at risk of EOS, as early recognition and treatment are essential to prevent morbidity and mortality. In a case of sibling of a patient with EOS in multigestation pregnancy, careful consideration of risk factors is warranted when deciding empiric investigation and treatment of an asymptomatic neonate. Finally, in the uncommon case of acute scrotal swelling in the neonatal period, although it is a surgical emergency due to risk of testicular torsion, infection is also an important differential diagnosis.

\section{Learning points}

- Early-onset neonatal sepsis is a condition with a high morbidity and mortality rate. Healthcare providers should be aware of the maternal and other risk factors and act early to treat empirically when it is suspected.

- Vertical transmission is the usual source of bacteria, causing early-onset sepsis. Close monitoring of asymptomatic siblings of patients with sepsis in multigestational pregnancy is necessary and should have a low threshold for investigation and intervention.

- Awareness of diversity of Escherichia coli clinical presentations is essential for the healthcare practitioners as it will guide the antibacterial treatment.

- Scrotal abscess is a rare finding in neonates but should be considered on the differential for acute scrotal swelling in the neonatal period; however, urgent surgery is still required as testicular torsion usually cannot be ruled out clinically.

Contributors DE: data collection, literature review, manuscripts draft preparation, directly involved in the patient care. VMS: manuscript edition, literature review, directly involved in the patient care. KK: manuscript edition, directly involved in the patient care. SD: manuscript edition, directly involved in the patient care.

Funding The authors have not declared a specific grant for this research from any funding agency in the public, commercial or not-for-profit sectors.

Competing interests None declared.

Patient consent for publication Obtained.

Provenance and peer review Not commissioned; externally peer reviewed.

Open access This is an open access article distributed in accordance with the Creative Commons Attribution Non Commercial (CC BY-NC 4.0) license, which permits others to distribute, remix, adapt, build upon this work non-commercially, and license their derivative works on different terms, provided the original work is properly cited and the use is non-commercial. See: http://creativecommons.org/ licenses/by-nc/4.0/

\section{ORCID iDs}

Veronica Mugarab Samedi http://orcid.org/0000-0002-7697-0893

Kaarthigeyan Kalaniti http://orcid.org/0000-0001-8378-0329

\section{REFERENCES}

1 Jefferies AL. Management of term infants at increased risk for early-onset bacterial sepsis. Paediatr Child Health 2017;22:223-8.

2 Sgro M, Campbell DM, Mellor KL, et al. Early-Onset neonatal sepsis: organism patterns between 2009 and 2014. Paediatr Child Health 2020;25:425-31.

3 American Academy of Pediatrics. Group B Streptococcal Infections. In: Kimberlin DW, Brady MT, Jackson MA, et al, eds. 2018 report of the Committee on infectious diseases. Red Book, 2018: 762-8.

4 Almidani E, Jefferies A, Khadawardi E. Evaluating twins at risk for sepsis: the dilemma of the well-appearing co-twin. J Clin Neonatol 2015;4:164-8.

5 Schrag SJ, Farley MM, Petit S, et al. Epidemiology of invasive early-onset neonatal sepsis, 2005 to 2014. Pediatrics 2016;138:e20162013.

6 Baird R, Puligandla PS, Laberge J-M. Congenital lung malformations: informing best practice. Semin Pediatr Surg 2014;23:270-7.

7 American Academy of Pediatrics. Serious bacterial infections caused by enterobacteriaceae. In: Kimberlin DW, Brady MT, Jackson MA, et al., eds. 2018 report of the Committee on infectious diseases. Red Book, 2018: 328-31.

8 Connell TG, Rele M, Cowley D, et al. How reliable is a negative blood culture result? Volume of blood submitted for culture in routine practice in a children's Hospital. Pediatrics 2007:119:891-6.

9 Elder JS. Disorders and Anomalies of the Scrotal Contents. In: Nelson textbook of pediatrics. Philadelphia, PA, 2020: 2827-33. http://www.clinicalkey.com/\#!/content/ book/3-s2.0-B9780323529501005605

10 Chiang M-C, Chen H-W, Fu R-H, et al. Clinical features of testicular torsion and epididymo-orchitis in infants younger than 3 months. J Pediatr Surg 2007;42:1574-7

11 Caesar RE, Kaplan GW, Caesar Richard E. The incidence of the cremasteric reflex in normal boys. J Urol 1994;152:779-80.

12 Dogra VS, Gottlieb RH, Oka M, et al. Sonography of the scrotum. Radiology 2003;227:18-36.

13 Huang CB, Chuang JH. Acute scrotal inflammation caused by Salmonella in young infants. Pediatr Infect Dis J 1997:16:1091-2.

14 Di Renzo D, Pappalepore N, Colangelo M, et al. Bilateral scrotal abscesses caused by Klebsiella pneumoniae in a newborn. J Pediatr Surg 2010;45:e19-20.

15 Cetinkaya M, Buyukkale G, Payasli M, et al. An unusual cause of bilateral scrotal abscess in a preterm infant: Candida albicans. Braz I Infect Dis 2013:17:260-2.

16 Malkin RB, Joshi VV, Koontz WW. Bacterial orchitis, abscess and sepsis in a newborn: a case report. J Urol 1974:112:530-1.

17 Hendricks WM, Kellett GN. Letter: scrotal mass in a neonate: testicular abscess. Am J Dis Child 1975;129:1361-2

18 Chiang M-C, Wang T-M, Fu R-H, et al. Early-onset Escherichia coli sepsis presenting as acute scrotum in preterm infant. Urology 2005;65:389.

19 Stark JE, Bellman LA, Kamel SH, et al. Escherichia coli Bacteremia, Epididymo-Orchitis, and Scrotal Abscess in a Neonate. J Pediatric Infect Dis Soc 2012;1:340-2.

20 Raveenthiran V, Cenita S. Scrotal abscess mimicking testicular torsion in infants and neonates. J Pediatr Surg 2007;42:597-8.

Copyright 2021 BMJ Publishing Group. All rights reserved. For permission to reuse any of this content visit

https://www.bmj.com/company/products-services/rights-and-licensing/permissions/

BMJ Case Report Fellows may re-use this article for personal use and teaching without any further permission.

Become a Fellow of BMJ Case Reports today and you can:

- Submit as many cases as you like

- Enjoy fast sympathetic peer review and rapid publication of accepted articles

- Access all the published articles

- Re-use any of the published material for personal use and teaching without further permission

Customer Service

If you have any further queries about your subscription, please contact our customer services team on +44 (0) 2071111105 or via email at support@bmj.com.

Visit casereports.bmj.com for more articles like this and to become a Fellow 